\title{
ESCRIBIR CON NIÑ@S: UNA POSIBILIDAD DE COAUTORÍA EN LA INVESTIGACIÓN ETNOGRÁFICA
}

\author{
Diana Milstein ${ }^{1}$
}

\section{Resumen}

Este artículo muestra cómo dos grupos de niñ@s de una escuela primaria en una localidad del conurbano sur bonaerense, Argentina, participaron como interlocutores, entrevistadores, observadores y co-autores en el trabajo de campo etnográfico que realicé durante los años 2004 y 2005. Junto con 1@s niñ@s editamos dos textos que contienen versiones de los "otros" y de los autores acerca de la localidad. Ambos reúnen de manera polifónica un conjunto de historias y comentarios de adultos, jóvenes, niños y niñas, de edades, procedencias, familias y ocupaciones diversas. Con un tono descriptivo y narrativo que incluye mapas dibujados por 1@s niñ@s e imágenes fotografiadas, los textos ofrecen versiones inteligibles de la vida social local. Mediante la descripción del estos procesos de trabajo y de producción de los textos, desarrollo un análisis de las particularidades de la coautoría con estos niñ@s. Luego discuto aspectos relacionados con la capacidad de

\footnotetext{
${ }^{1}$ Doctora en Antropología Social por la Universidad Nacional de Brasilia, Magister en Antropología Social por la Universidad Nacional de Misiones, Profesora de Enseñanza Primaria y Profesora de Expresión Corporal. Se desempeña como Profesora Regular e investigadora de la Facultad de Ciencias de la Educación de la Universidad Nacional del Comahue y como Investigadora Adscripta del Instituto de Desarrollo Económico y Social (IDES). Ha investigado sobre temas vinculados a educación y Antropología y sus relaciones con la niñez, el cuerpo, la salud, el arte y el método etnográfico. Dicta cursos de postgrado como profesora invitada en programas de distintas universidades nacionales en la Argentina sobre temas de su especialidad. Es autora de los libros La escuela en el cuerpo. Estudios sobre la construcción social del alumno en escuelas primaria, con Héctor Mendes (Madrid, Miño y Dávila, 1999), Higiene, autoridad y escuela. Madres, maestras y médicos. Un estudio sobre el deterioro del Estado (Buenos Aires, Miño y Dávila, 2003) y La nación en la escuela. Viejas y nuevas tensiones políticas (Buenos Aires, Miño y Dávila-IDES, 2009) Autora de diversos artículos publicados en compilaciones, revistas académicas y de difusión política-cultural del país y del extranjero, entre los más recientes se encuentra "Politics is also "child's play'", en Teaching and Teacher Education y "La escuela, territorio urbano en disputa en Cuadernos del IDES.
} 
agenciamiento de $1 @$ s niñ @s en tanto intérpretes y autores y propongo modos innovadores y creativos de interactuar participativamente con $1 @ \mathrm{~s}$ niñ @s, modos que también pueden impactar procesos educativos.

Palabras clave: Etnografía; trabajo de campo; niñ@s como coautores; experiencia educativa.

\section{Introducción}

Este libro ["Averiguando algo más: Leyendo la historia de nuestro barrio y de nuestra escuela"] es el producto de un trabajo que realizamos con un grupo de alumnos de la escuela 40 durante los meses de septiembre y octubre de 2004 que denominamos "Lección de Paseo Antropológico". Se realizó fuera del horario escolar, la participación fue voluntaria, cada uno de los chicos aportó a la tarea todo lo que pudo y deseó, las reuniones las hicimos en la escuela y los paseos, por algunos lugares de La Florida.

¿Por qué antropológico? Porque intentamos conocer quiénes somos, qué hacemos, cómo vivimos, qué pensamos, que nos gusta y que nos desagrada a los vecinos de La Florida a través del relato de distintas personas y dando lugar a las distintas versiones de lo que nos iban contando. La idea es conectarse con aspectos culturales de la existencia social y colectiva de quienes viven en el barrio, vincular relatos de lo que sucedió antes con relatos de lo que sucede actualmente.

¿Por qué Paseo? Porque caminando y andando en grupo crecen las ganas por saber y conocer, pasear es aprovechar nuestro tiempo.

¿Por qué Lección? Porque fue una manera de llamar a esta forma de iniciar a un grupo de chicos en el conocimiento social.

Durante cada una de estas lecciones los chicos hicieron distintas actividades. Imaginaron y dibujaron el plano de La Florida, analizaron y seleccionaron los lugares más importantes que necesitaban visitar, eligieron las personas a entrevistar, observaron y fotografiaron lugares cercanos conocidos $y$ desconocidos, de este modo obtuvieron los "documentos" con los que se organizó este libro. Pero no bastó con tener los documentos, también fue necesario leerlos, analizarlos y decidir qué fragmentos eran los principales, así como imaginar la organización y el armado de esta publicación.

Fue así, trabajando que se constituyó este grupo de "antropologuitos" que con mucho compromiso se animaron a llevar adelante esta experiencia colectiva, cuyo único objetivo fue y es desarrollar el gusto por conocernos. (Milstein coord; 2004: 3-4)

La cita con la que comienza este artículo es un fragmento de la introducción que escribí para una publicación titulada "Averiguando algo más: Leyendo la historia de Revista Reflexão e Ação, Santa Cruz do Sul, v.18, n2, p.65-91, jul./dez. 2010 
nuestro barrio y de nuestra escuela". Se trata de un pequeño texto que escribimos con un grupo de alumnos y alumnas de una escuela primaria de un barrio situado en una localidad del conurbano bonaerense, como resultado de un trabajo de campo compartido en el año 2004. Durante el año 2005, nuevamente realicé trabajo de campo con niñ@ s de la misma escuela y en la misma localidad y escribimos otro texto. Estas experiencias de trabajo en colaboración quedaron situadas en el corazón de mi proceso etnográfico y enriquecieron todos los aspectos de mi investigación. Y lo más relevante de estas experiencias fue que dieron lugar a reelaborar las relaciones con el objeto de estudio y con mis interlocutores-no solamente chic@s. Ese periodo de trabajo con niñ@s me condujo luego a repensar las tareas que desarrollé en campo, el tratamiento de temas, la interpretación de las situaciones, la escritura de resultados y también los modos de difusión de resultados.

En este artículo, a continuación, presento una breve reseña de la investigación que incluyó las experiencias mencionadas y describo el proceso de trabajo de producción de los textos junto con el análisis de las particularidades de la coautoría con estos niñ@ @. Luego discuto aspectos relacionados con la capacidad de agenciamiento de 1@s niñ@s en tanto intérpretes y autores y propongo modos innovadores y creativos de interactuar participativamente con $1 @ \mathrm{~s}$ niñ@s, modos que también pueden impactar procesos educativos.

\section{Mis primeros diálogos con los chicos}

Durante los años 2004 y 2005 desarrollé trabajo de campo en Villa La Florida -una localidad del distrito de Quilmes, zona sur del Gran Buenos Aires, Argentina- y una gran parte del mismo en la escuela primaria estatal más antigua de esa localidad. Los alumnos y las alumnas que iban a esa escuela eran hijos e hijas de familias de trabajadores, muchos de 
los cuales desde mediados de la década del noventa habían quedado desocupados. Muchas de esas familias vivían en las áreas más pobres de la localidad. El empobrecimiento y la desocupación habían transformado los estilos de vida familiares y la relación de las familias entre sí y con los vecinos. En el texto editado con los niños en 2004, esta situación quedó ilustrada con un fragmento de una entrevista realizada a una vecina que contó cómo habían paliado las circunstancias algunos trabajadores y trabajadoras de la localidad:

\begin{abstract}
"Esta feria hace tres años que está funcionando, empezamos con un grupito chiquitito, con mucha vergüenza al principio, vergüenza porque venimos todos de estar trabajando en fábricas, en oficinas, y bueno después te agarra la desocupación, el cierre de fábricas. Y entonces dijimos bueno, armemos una pequeña feria y empezamos. Ya te digo éramos diez y de diez hoy somos 180' puesteros que trabajamos entre sábados y domingos, son todos de Quilmes, se apunta a que seamos todos del barrio,. - No es por discriminar, es porque esto se hizo a base de sacrificio de muchos de bancarnos frío, nos hemos comido cada invierno terrible, del compañerismo de los vecinos que los vecinos salieron y dijeron está bien, apoyemos porque somos vecinos, no nos pongamos en contra (Vecina)" (Milstein coord; 2004: 18-19)
\end{abstract}

El propósito general de mi investigación era examinar las prácticas escolares en su dimensión política, en el contexto de la desorganización y la desestructuración que produjo la crisis económica política y social de los noventa en la Argentina. Describí prácticas políticas presentes en la vida cotidiana de la escuela primaria estatal, desplegadas por una pluralidad de actores sociales que intervienen y producen -o son parte- de tensiones y disputas políticas nunca restringidas a la vida escolar ${ }^{2}$. Entre esos actores descubrí a niños y niñas y me sorprendí cuando pude verlos como actores sociales, como agentes, capaces de desarrollar prácticas orientadas a producir efectos políticos ${ }^{3}$.

2 Esta investigación la realicé entre los años 2004 y 2007 en el marco de mi tesis de doctorado en la Universidad de Brasilia y bajo la orientación de la Dra Rita L Segato.

${ }^{3}$ Sobre este aspecto de mi trabajo de investigación con niños, que no desarrollo en este artículo, puede consultarse Milstein (2008, 2009 y 2010)

Revista Reflexão e Ação, Santa Cruz do Sul, v.18, n2, p.65-91, jul./dez. 2010 
El hecho que llamó mi atención sobre esto sucedió durante el primer mes de mi trabajo de campo. Tuve un encuentro casual con una alumna de quinto grado de la escuela durante una clase de Educación Física que se desarrollaba en el patio. Ella estaba de observadora -por razones de salud no podía desarrollar actividad física- y, probablemente, un poco aburrida, de modo que mi presencia despertó muchas ganas de contar y entre otros relatos me dijo:

"Tuvimos muchas maestras y a una suplente la echamos porque pegaba, era mala y siempre gritaba y empujaba a los chicos. A mí me golpeó ese día que la echamos, me empujó contra el armario y me golpeó acá [señala el hombro] También lo golpeó a ese que está con la pelota [señala a un chico] y tiraba del pelo ...Gritamos todos para que se vaya y vinieron maestras y todo, y la sacaron”.'( Diario de campo 10-04-04)

Durante el tercer mes de trabajo de campo, me detuve a releer mis notas de campo. Entonces, advertí la importancia que tenían los diálogos que, en varias ocasiones y de manera casual, había entablado con diferentes chicos. Hay que tomar en cuenta que en mi proyecto inicial y durante la primera etapa de mi trabajo de campo, yo había definido a los adultos -docentes, no docentes, familiares, vecinos- como los interlocutores privilegiados. Presuponía que eran estos los actores sociales que podían involucrarse de algún modo en la vida política de la escuela. Recordemos que el campo es un recorte de lo real construido activamente en la relación entre el investigador y sus interlocutores (Guber; 2001: 84) y cuando un grupo social está en una zona de invisibilidad para los ojos de la investigadora queda "naturalmente" fuera de juego. Esto muestra de manera muy clara que "cuando hacemos antropología de "nuestras" sociedades, el reconocimiento de la 'presencia' es problemático precisamente porque parece no tener 'nada que decir' y está cubierto por silencio. Es un silencio que invisibiliza el hecho que la presencia es siempre una cuestión 
crítica porque la co-presencia está siempre mediada por lo que denominamos nuestros 'enfoques' o 'abordajes' (Fabian, 2007:116). En el caso de mi estudio, el enfoque o abordaje de dos nociones - política y niñez- con el valor agregado del adultocentrismo, se interponían en la co-presencia con los niñ@s. Por otro lado, me benefició haber aprendido que todo lo que me sucede, veo y escucho debo dejarlo registrado de alguna manera. Por eso fue posible retomar la lectura de lo que me habían dicho algunos niñ@s y conectarlo con temas y cuestiones fundamentales para mi estudio. Así, a la distancia, frente a mi cuaderno y mi computadora, comencé a incorporarlos como interlocutores.

Llegó el cuarto mes y volví a la escuela, decidida a programar actividades de campo con alumnos y alumnas de la escuela. Comenté mi idea con la directora de la escuela y la maestra secretaria -personas con las cuales solía mantener largas y asiduas conversacionesy me propusieron que presentara una actividad concreta que se encuadrara dentro del Proyecto Educativo Institucional ${ }^{4}$, centrado en el eje temático identidad, y ellas me darían todo su apoyo.

Presenté un proyecto para coordinar un taller con alumnos combinado con un seminario para docentes, que denominé "Construyendo identidades a escala local: los chicos como antropólogos". El taller se desarrollaría durante seis semanas y estaba previsto entrenar a alumnos y alumnas para realizar observación participante y entrevistas de manera similar al trabajo de campo de los antropólogos. Estas actividades se combinarían con reuniones grupales semanales en las que se organizarían modos de recolección de la información, se compartirían las experiencias de observación y entrevista, y se

\footnotetext{
4 Las escuelas de la provincia de Buenos Aires deben formular todos los años un PEI (Proyecto Educativo Institucional) que enuncia una programación general alrededor de un eje temático central, a ser desarrollada por cada uno de los docentes a través de actividades concretas destinadas a algunos cursos y/o a toda la escuela.
}

Revista Reflexão e Ação, Santa Cruz do Sul, v.18, n2, p.65-91, jul./dez. 2010 
introducirían trabajos gráficos y escritos. Por su parte los docentes además de participar del seminario podían compartir cualquier instancia de actividad con los alumn@s. También estaba previsto como culminación del trabajo en taller, que yo presentara un informe elaborado con la colaboración de $1 @$ s alumn@s. Mi aspiración era constituir un espacio de interlocución duradero con un grupo de alumn@s, que me permitiera estar y pensar con ellos para reconstruir sus puntos de vista y perspectivas $\mathrm{y}$, crear oportunidades de experimentar una situación de aprendizaje diferente para ellos y para mí. Llevé a cabo estas actividades con dos grupos, uno entre los meses de septiembre y noviembre del año 2004 y el otro, desde septiembre hasta diciembre del 2005. Llevar a la práctica lo proyectado superó absolutamente lo que había podido imaginar antes de comenzar.

\section{El proceso de organización y trabajo colectivo}

Durante los primeros dos meses, con ambos grupos, caminamos por distintos lugares del barrio y visitamos instituciones, comercios y hogares donde desarrollamos actividades de observación, observación participante, entrevistas grabadas y registro fotográfico. También mantuvimos periódicas reuniones grupales durante las que conversábamos y los chicos diseñaban planos de sectores de Villa la Florida. Mi trabajo específico con ellos consistió en organizar actividades para entrenarlos y perfeccionar las diversas actividades, coordinar las conversaciones grupales, participar en las entrevistas y en las situaciones en que se observaba y participaba, desgrabar entrevistas y conversaciones, revelar y copiar las fotografías, además de tomar notas y registrar todo lo que podía.

Al repensar todo el proceso llevado a cabo con ambos grupos en términos de la producción de textos creados colectivamente, pude ver que transitamos tres grandes etapas.

Revista Reflexão e Ação, Santa Cruz do Sul, v.18, n2, p.65-91, jul./dez. 2010 
La primera consistió en la coorganización del proyecto; la segunda, en la coparticipación en el trabajo de campo y la tercera, en la coproducción de textos. Durante la primera etapa, realizamos actividades tendientes a lograr un intercambio de ideas entre el grupo de niños y yo para decidir qué haríamos juntos, quiénes participarían, cómo organizaríamos nuestras actividades. El tema que integró las inquietudes conjuntas con ambos grupos, fue conocer el lugar en el que vivían, a través de lo que les podían contar personas de Villa La Florida. Yo les conté el tema de investigación, pero no fue ese relato lo que les entusiasmó, sino las actividades concretas -visitar lugares que ellos eligieran, entrevistar y grabar, fotografiarque asimilaron a las de los periodistas de la televisión que realizan notas por la calle. Les gustó estar en la escuela fuera del horario habitual: "tenemos las escuela para nosotros", decían. Prácticamente todas las actividades las hicimos fuera del horario escolar y utilizando espacios que no eran los que habitualmente utilizaban para las actividades escolares. Durante este primer período, también fuimos estableciendo los roles de cada uno. Esto era fundamental para mí, porque tenía que encontrar modos concretos de evitar que mi lugar fuera el que "naturalmente" se producía en las interacciones: enseñante, cuidadora. Para eso durante las primeras reuniones enfaticé de manera muy explícita mi ignorancia con relación al lugar y a la gente que vivía allí: les pedí a los niños que dibujaran un plano para mostrarme los lugares que querían visitar, dónde estaban situadas sus casas y las de sus familiares. Mientras dibujaban, me contaban. Así, yo fui conociendo una Villa la Florida desconocida hasta el momento. Conocí la vida social de la plaza, a los bomberos, otras escuelas, chicos y chicas de otros barrios y también a Fernando, una persona que vivía en la calle desde hacía aproximadamente cuarenta años, muy reconocida por los vecinos y 
significativa para la localidad. En el primer libro, quedó registrada la presencia de Fernando:

\begin{abstract}
FERNANDO: NUESTRO "PATRIARCA"
Allá lejos y hace tiempo

Fernando apareció un día, yo tenía trece o catorce años. Apareció caminando por Belgrano, vivía abajo del puente. Ex alumna y auxiliar de la escuela 40

Fernando es toda una institución.

¡Todos lo quieren! Yo me acuerdo que iba a tomar un colectivo y pasó un camión y me gritaron groserías y él agarró y los corrió a los del camión y les dijo a la chica no le digan nada, ella no les hizo nada.. Vecina y Auxiliar de la escuela 40)

Es muy buena persona Fernando. La gente lo quiere muchísimo, tiene gente que le da de comer, es como que no es un vagabundo cualquiera, desconocido. Es un vagabundo de la zona que se quedó acá y vive acá. Madre de Cooperadora de la escuela 40 (Milstein coord., 2004: 26-27)
\end{abstract}

Durante la segunda etapa y para poder realizar con los niñ@s trabajo de campo, realizamos ejercitaciones jugando a preguntar y responder, las grabábamos y luego las escuchábamos. Entre risa y risa, yo hacía mis sugerencias. También se llevaron a sus casas el grabador para hacer entrevistas a sus familiares, que luego escuchamos y comentamos en grupo. Las salidas con el primer grupo fueron ocho e incluyeron la plaza y la feria, casas de vecinos, centro de salud, Bomberos Voluntarios. Con el segundo grupo también fuimos a la plaza y a visitar casas de vecinos, además de visitar el centro comercial -lugar de esparcimiento y de compras de los pobladores de la localidad- y otros espacios verdes. En cada lugar sacaban fotos, organizaban juegos, entrevistaban y conversaban entre ellos. Los juegos siempre implicaban modos de participación. En la feria, sumándose a algún puesto para acomodar lo que se vendía y también comprando; en el centro de salud, aprovechando que estaba ya fuera de horario de atención, jugando al médico y los pacientes con las camillas y usando el estetoscopio, en el centro comercial jugando a "salir de compras". Las entrevistas eran, por lo general, el momento más formal y solicitaban mi ayuda para 
empezar y, a veces, también para finalizar. Al principio porque se inhibían y al final, cuando se aburrían de la conversación.

Coproducir el texto ocupó el último período para ambos talleres. Lo dedicamos a organizar textos que en principio yo había imaginado como informes para la escuela y que acabaron siendo pequeños libros, parecidos a folletos, armados de manera artesanal y doméstica, destinados a otros chicos, familiares, vecinos y docentes. Para componer estos textos los chicos seleccionaron fragmentos de las desgrabaciones usando el estilo "recortar y pegar", seleccionaron fotografías, organizaron índices temáticos, colocaron los títulos, escribieron algunas pocas frases y revisaron borradores de los textos antes de la edición final. Yo participé coordinando estas actividades, escribiendo y transcribiendo en la computadora -en esta escuela los niños no tenían a disposición equipos de computación-, colaborando con la lectura y la selección, y editando los libros.

A diferencia del primer texto en el que yo escribí la introducción -con la que comencé este artículo-, en el segundo, llamado "Así vemos La Florida", los chicos decidieron colocar partes de una conversación que mantuvimos en una de las sesiones de trabajo grupal. Para componer este texto escrito los chicos recibieron la desgrabación completa de esa reunión y cuando la leyeron les pareció que sería lo mejor para la introducción. Leían la desgrabación de manera individual, o de a dos, y marcaban con un lápiz de color las partes para adicionar y armar el texto para la introducción. Luego, yo recorté y pegué cada fragmento elegido en forma consecutiva, lo edité y lo imprimí. Ellos volvieron a leerlo, quitaron más fragmentos y reubicaron algunos "para que se entendiera mejor de qué se hablaba". En el último armado yo agregué signos de puntuación que me 
parecieron necesarios y cambié algunos tiempos verbales para acomodar el lenguaje oral al escrito.

Fragmentos de la introducción servirán para ilustrar el proceso de coproducción del texto que en todos los casos comenzó y se desarrolló grabando situaciones de lenguaje oral. En el caso de esta introducción comenzó cuando nos reunimos a recordar lo que ya habíamos realizado. Fue un momento de reflexión grupal, muy entretenido tanto para los chicos como para mi, seguramente porque al contarnos revivimos los momentos más intensos del proceso.

Un día nos reunimos para contar entre todos, historias de nuestro trabajo. Yanina le pidió a Diana que hiciera preguntas para que contar, fuera más fácil:

Diana: - ¿Se acuerdan de la primera reunión que tuvimos el año pasado?

Yanina: - Estábamos con Aldana, Soledad y Juanita, éramos cuatro y estuvimos haciendo el plano. Después ellas ya no vinieron más y quedé sola y después los llamé a Rodrigo y a Daniela. ¿Y se acuerdan que casi nos tiran el plano al tacho acá en la escuela?

Daniela:- y vos, Yanina, no sé lo que me dijiste para que me uniera a ustedes. Era una mentira.

Yanina: -Que era para la tele, le dije.

Daniela: -Después vine y te encontré a vos Diana y me encantó.

Diana: -Me parece que me encontraste en la plaza.

Yanina: - Sí, yo me acuerdo cuando estuvimos con la abuela Sabina que dijo que casi agarra a los chicos porque estaban arriba de los árboles

Daniela:- Y yo me acuerdo cuando estuvimos conversando adentro con los bomberos y después vimos a tu papá, ¿no Rodrigo?

Yanina:- Y también fuimos con Micaela a la Salita y Micaela se tiraba arriba de las camillas, el año pasado.

Daniela: -Y este año vinimos al bingo en la escuela.

Yanina: -Tenía una suerte la señorita Silvia, se sacó todo.

Daniela: - A mi me faltaba un número.

Diana:- Y no quisieron hacer ninguna entrevista durante el Bingo.

Daniela: -No, nos daba vergüenza. Y después yo me vine a mi casa y ustedes se fueron al parque.

Yanina: -Estuvimos poco porque estaba todo embarrado allá.

Daniela: -Y también cuando le hicimos las entrevistas a los chicos en la escuela.

Leonor: -Les preguntamos quiénes eran sus amigos, por los compañeros del colegio.

Daniela: -Cómo era su barrio, si había plaza, si no había plaza.

Daniela:- Y también cuando fuimos todos a la plaza, a la de la Casona. Y que estaban esos chicos que nos querían asustar.

Yanina: - Si, y cómo gritaban. Y después nos sacamos una foto, todos. Y estaba el perro muerto y Rodrigo quería que le saque una foto.

Yanina:- Y después volvimos todos juntos y queríamos parar el colectivo para que suba Diana. 
Camila: - Pero tenía que ir a la parada.

Daniela: - Y cuando volvimos nos comimos algunos nísperos.

Rodrigo: - Estaban re verdes.

Camila: -Estaba la casa con rejas.

Yanina: - Si salía la señora, nos iba a correr con la escoba.

Diana: -¿Qué les gusta hacer de esta actividad a cada uno?

Yanina:- Y, no sé, salir a la calle, dar vueltas.

Rodrigo: - Sacar fotos.

Camila: - Me gusta el tema que está trabajando usted, me gusta investigar y me enganché y estuvo bueno.

Yanina: - También conocer la gente hablando y sacar fotos.

Daniela: - Y que salga el librito es relindo.

Yanina: - Y seguro que cuando esté, alguien lo va a leer.

Yanina:- A mi mamá y a mi papá les gusta lo que hacemos nosotros. Ya que no se puede hacer ningún deporte ni nada, que estemos entretenidos en algo que nos parece bien.

Camila: -A mí lo que más me gusta es hacer entrevistas a la gente.

Leonor: -Me gusta así visitar muchos lugares y estar con la gente. Porque a mí no me dejan salir mucho. (Milstein coord.; 2005; 4-7)

\section{El proceso de coproducción de textos}

La composición de la parte escrita de ambos textos se realizó de la misma manera en que se trabajó para organizar la introducción que cité anteriormente.

Cuando completamos el período de salidas de campo con el primer grupo, invité al equipo de chicos a reunirnos para empezar a organizar el libro. Recuerdo que las miradas de los chicos fueron de absoluta perplejidad, supongo que con el entusiasmo de las salidas, las entrevistas, las grabaciones y las fotografías habían perdido de vista esa cuestión. Yanina, una de las chicas que tenía más iniciativa, me preguntó cómo haríamos y agregó: “yo nunca vi un libro escrito por chicos. Mi papá trabaja en la imprenta y trae muchos

libros a mi casa y no hay escritos así por chicos". Para dar tranquilidad contesté que había libros con partes escritas por chicos y también yo tenía un libro que había escrito una persona grande con chicos y que se los iba a llevar a la reunión para que lo vieran. El libro 
era "Voices from the fields. Childrens of Migrant Farmworkers tell theirs histories", estaba publicado en EEUU y se trataba de una edición de muy buena calidad. Yo no contaba con ningún recurso extra y por lo tanto no podía proponerme algo como ese objeto, pero me pareció que era estimulante compartir su lectura. Como el libro estaba realizado con textos de niños hijos de mexicanos, hay partes que están escritas en español y además tiene muchas fotos. De modo que algunas partes las leyeron ellos, otras las miraron, y las que estaban en inglés intentaron entender a partir de lo que habían aprendido en sus clases en la escuela y yo los ayudé. El libro les gustó mucho y no necesité explicarles que nosotros no podíamos hacer una publicación como esa. No fue la única vez que este equipo de trabajo me mostró una actitud completamente realista con relación a los recursos disponibles, lo que no es lo mismo que decir que se conformaban con facilidad.

El libro dio vueltas entre los chicos. De pronto, Daniela comentó: "vamos a tener que poner un título". Yanina agregó, "y un índice” y Rodrigo me miró y haciendo un gesto con la mano bastante cómico, me preguntó: "y cómo se hace un índice, eso nosotros, nada". A esa altura yo sentía una felicidad inmensa, las preguntas no podían ser más pertinentes, estaba segura que íbamos a poder escribir juntos. Propuse entonces comenzar por el índice y para eso recordar los lugares que habíamos visitado y la gente con la que

\footnotetext{
${ }^{5}$ En este libro "Voces desde los campos. Hijos de granjeros migrantes cuentan sus historias", la autora, Beth Atkin, presenta testimonios de un grupo de niños y niñas de Salinas Valley, E.E.U.U., una localidad de inmigrantes mejicanos agricultores. La lectura de los testimonios de los niños, de sus poemas y las fotografías tomadas por la autora, introduce al lector con naturalidad en la vida social de este grupo de inmigrantes mexicanos. Todos los testimonios son en primera persona, narrados por niños, pero en todos los casos ellos hablan acerca de cómo se vive, cómo se trabaja, como se relacionan en familia, entre niños, entre hermanos, cómo piensan y perciben su lugar, etc. De este modo, muestra con elocuencia la capacidad para narrar e informar acerca de la vida social en general que tienen estos pobladores, cuyas edades oscilan entre los nueve y los dieciséis años, incluso teniendo algunas dificultades originadas en el bilingüismo.
} 
habíamos estado. Surgió así una primera propuesta: la plaza, los bomberos, la escuela. Pregunté para qué fuimos a esos lugares y la respuesta dio origen al título del libro:

Daniela: para averiguar

Diana: qué?

Rodrigo: algo más que no sabemos

(Diario de campo, 21-10-04)

Durante el encuentro siguiente, tres días 1, comenzaron con el trabajo de leer y seleccionar. Ese día solamente participaron Yanina y Ezequiel porque los otros tenían diferentes inconvenientes. Comenzaron leyendo las entrevistas, Yanina recogió las realizadas en la plaza y Ezequiel las de la visita a Bomberos Voluntarios. Yanina subrayaba con color rojo y Ezequiel, con azul. No dialogaban, hasta que Yanina preguntó si podían escuchar música porque ella tenía dos CD. Ezequiel los miró y eligió el que tenía música de cumbia. Continuaron leyendo mientras escuchaban, se balanceaban, marcaban el ritmo con la mano y también cantaban algunas estrofas. Ya había pasado una hora aproximadamente y Ezequiel preguntó cómo marcaba lo que va con la escuela, porque había un fragmento de lo que estaba leyendo que no correspondía ponerlo con los bomberos. Intercambiamos entre los tres ideas ante esta dificultad, porque también Yanina advirtió que en las entrevistas de la plaza, las personas hablaban de la escuela y de otros temas. Decidieron usar otros colores para diferenciar, y continuaron leyendo, subrayando y escuchando música una hora más. Mientras tanto yo miraba lo que leían y subrayaban y me interesé por saber los criterios que usaban para elegir los fragmentos. Como me costaba imaginarme, intenté preguntar, pero no se interesaron en absoluto por mi preocupación. Contestaban con frases sueltas del tipo: "porque es importante", "es divertido", "me parecioo", "no sê". A la reunión siguiente fui con la selección de textos rearmada por colores según me habían indicado. Eran cuatro 
colores y por lo tanto cuatro textos separados: a uno lo nombraron la plaza, al otro la escuela, al tercero los Bomberos y al cuarto, el barrio. Les comenté que era muy largo para el tamaño de libro que haríamos y comenzaron nuevamente a marcar fragmentos. Mientras leían, Daniela recordó a Fernando y dijo que ella quería que estuviera lo que decían de él. Así surgió el quinto apartado. Entre lectura y lectura también miraban las fotos que habían sacado - tenían copias de cada una- e iban seleccionando para cada parte algunas (por un tema de costos, tuvieron que reducir al mínimo esta selección). Lo que siguió fue otra relectura, y conversaciones muy orientadas por mí para llegar al título definitivo y a los títulos y subtítulos de cada parte. También les pregunté a quiénes les querían agradecer la ayuda. Los chicos nombraron y yo escribí los agradecimientos. El final fue la presentación de cada uno que grabé y luego transcribí:

\section{Daniela Cejas:}

"Tengo 11 años. Tengo cuatro hermanos, un varón y tres chicas. Estudio en la escuela 40. Yo empecé segundo acá. Viví siempre acá y yo antes iba a la escuela Santa María que es del barrio. A mí me gusta esta escuela porque yo acá encontré mis amigas. A mí me gusta".

S. Ezequiel Miranda:

“Tengo 12 años. Tengo dos hermanas y un hermano. Además de la escuela, yo juego al fútbol en el club. Nosotros jugamos y también viajamos. Yo ya fui a tres escuelas Primero fui a la 1 de Quilmes porque mi mamá trabaja en la Biblioteca a la vuelta, después me vine a otra a la tarde y después, desde cuarto, vine acá a la mañana. Después quiero ir a la Técnica porque estás todo el día, a mi me gusta la Técnica".

\section{Fabián Franzone:}

“Tengo 13 años. Nací en La Florida. Siempre vine a esta escuela. Mi papá y mi mamá también vinieron a esta escuela. Mi abuelo era capataz de los Bomberos Voluntarios de la Florida".

Marisol Sosa:

"Nací en Varela y vine a La Florida cuando tenía dos años. Vivo con mi hermana, mi papá y mi mamá. Mi mamá es peluquera, mi papá es mecánico y mi hermano trabaja, es grande. Siempre vine a la escuela 40 , vivo cerca“.

Micaela Robledo:

"Tengo 11 años, voy a la escuela $\mathrm{N}^{\circ} 40$ Islas Malvinas. Tengo cinco hermanos, cuatro hermanos y soy la única nena. A la escuela vengo hace dos años, hice cuarto y quinto, por eso no conozco mucho el barrio."

Rodrigo Cejas:

“Tengo 11 años. Desde que nací, siempre viví en La Florida. Vivo con mis hermanos y mi papá y mi mamá. Mi papá trabaja y es bombero y mi mamá es depiladora. Antes iba al San José, me gusta venir esta escuela." 
Yanina Silva:

“Tengo 12 años, nací en Córdoba. Vine a La Florida a los 2 años. Somos cuatro hermanos, tres mujeres y un varón. Mi mamá trabaja en la Feria y mi papá es gráfico. Los dos son entrerrianos. Vengo a la escuela desde primer año.”

Para la selección de la tapa los chicos tuvieron la idea de colocar una foto de todos nosotros emulando el libro que habían visto. La idea que yo propuse fue tomar una foto del plano que ellos habían dibujado y aceptaron mi idea.

Con el segundo libro trabajamos de manera similar para componerlo y organizarlo. Pero, como el trabajo de campo que realizamos en esta segunda experiencia fue fundamentalmente con otros chicos, más que con adultos como en la primera, el resultado fue diferente. Lo que marca esa diferencia es la combinación de fragmentos de entrevistas con niños y niñas y relatos de esos mismos niñ@s, junto con diálogos y relatos de los integrantes del grupo. En esta combinación también ingresó lo que hacían y opinaban los adultos próximos -especialmente familiares y vecinos- a través de lo que decían 1@s niñ@s..

\section{Los niñ@s intérpretes y co-autores}

Los libros fueron impresos en un tamaño de media hoja A4 en papel común y en colores. El primero, “Averiguando algo más. Leyendo la historia de nuestro barrio y de nuestra escuela", tiene 48 páginas. El segundo, “Así vemos la Florida”, tiene 40. La tapa del primero presenta el diseño de la plaza tomado del plano dibujado por el grupo de chicos, arriba del mismo, el título del libro y debajo, los nombres de cada uno de los autores, incluida yo como coordinadora. En el caso del otro, el diseño ocupa la tapa y la contratapa e incluye una explicación sobre el mismo. En la primera hoja se presenta una foto de todo el grupo y los nombres de cada uno. La página siguiente para ambos es el 
índice. El primer texto está dividido en siete pequeños capítulos: Introducción, Agradecimientos, Conocemos la plaza, Anécdotas de los bomberos, Fernando: nuestro "patriarca", Nuestra escuela, ¿Cómo se siente el barrio? El otro, en ocho apartados: Introducción, Las Escuelas, Los Lugares, Las Familias, Los trabajos de los Padres, La Política, Las Leyendas de Miedo, Cierre.

Los pequeños capítulos están organizados con fragmentos de conversaciones transcriptas, partes del mismo plano dibujado que se presenta al inicio y algunas fotos. Estas imágenes además de ilustrar la parte escrita, agregaron un aspecto de lo vivido y lo imaginado por el grupo. Recordemos ese diálogo que transcribí más arriba, en el que Rodrigo dijo que averiguaron algo más que no sabían. Esta frase es para mí muy significativa en términos de colaboración en la autoría de los libros, porque explicita la posición compartida en ese mundo social que salimos a explorar y sobre el que decidimos contar.

Lo más descriptivo/narrativo de ese algo más está especialmente en la parte escrita, lo vivido especialmente en las fotos y lo imaginado, sobre todo, en el diseño dibujado. El último capítulo del primer libro -“¿Cómo se siente el barrio?”- está compuesto por siete fragmentos de narraciones de entrevistados, tres fotos y cuatro imágenes de partes del plano dibujado. Los fragmentos narran breves historias en primera persona relacionadas con la llegada a la localidad, el proceso de urbanización, el centro de salud, el arroyo “cuando sus aguas eran cristalinas", la comunidad vecinal.

En las cuatro imágenes está representada la zona en la que viven varios de ellos, con las casas dibujadas, los kioscos en los que compran habitualmente, y una pequeña fábrica de dulces que al lado tiene un espacio denominado por los adultos como "baldío". Ese 
espacio, como se puede apreciar en la imagen, está representado por dos árboles y una flor. Pasamos por allí dos veces con los chicos y en ambas oportunidades corrieron y saltaron allí del mismo modo que en la plaza y me lo contaron como un lugar de juego.

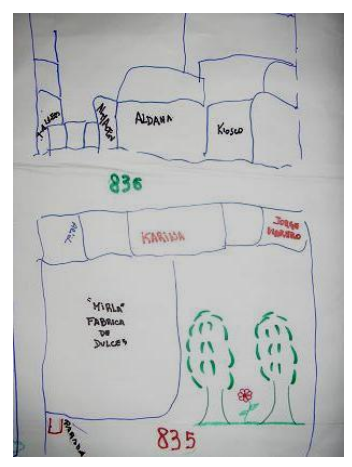

La fotografía que eligieron del centro de salud abunda en vivencia. Recordemos que durante esa visita la actividad más importante fue jugar a ser doctora y paciente y en la imagen está Micaela -la doctora- despidiendo a Yanina, su paciente. Si bien este juego no está contado en el libro, la imagen de esta niña en la puerta de la Unidad Sanitaria, es reveladora de la irrupción del juego y de una redefinición de la imagen habitual de un espacio sanitario.

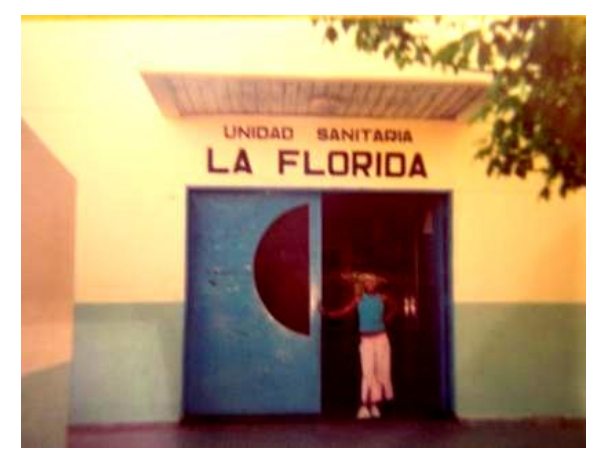

El significado que los chicos otorgan a las situaciones, los espacios y las personas a veces es similar al de los adultos. En estos casos, sus perspectivas suelen ser relativamente 
convencionales. Pero en ocasiones, como el caso del "baldío", se presenta como una contraposición espontánea frente al sentido naturalizado por los adultos.

Baldío significa espacio vacío, en el sentido común es un territorio donde no hay nada significativo, valioso, útil. Es un lugar que no sirve ni siquiera para el esparcimiento y, en las zonas urbanas, se espera que se lo vuelva productivo. Precisamente a ese espacio así definido, los niños lo experimentaban como un espacio cargado, productivo, placentero. Por eso, ese dibujo provoca en quien lo percibe una comprensión del goce próxima a la alegría que producía estar ahí, en ese lugar. Cuando percibimos, comprendemos o gozamos una representación, es como si estuviéramos percibiendo, comprendiendo o gozando el objeto representado (Sperber; 1992:26). Esto confirma que ese modo de representar el espacio contiguo a la fábrica era adecuado al modo en que era sentido y significado. Al mismo tiempo denota una franca oposición de significados entre la perspectiva de los adultos y la de estos niños que, lejos de derivarse de una distorsión infantil, emana del modo en que el espacio es percibido y vivido. Algo similar probablemente incidió para que los niños descartaran todas las referencias al arroyo como lugar contaminado, sucio, arruinado, y seleccionaran la única voz adulta que lo mostró desde un recuerdo de infancia, como lugar de placer y juego.

\footnotetext{
Una anécdota de cuando yo era chiquita, pero eso es de hace muchos años: yo tenía seis o siete años y tenía una amiguita al lado de casa que tenía nueve o diez y tenía otra que tenía once. Un día nos fuimos a caminar con los papás de ella. Llegamos al arroyo todo el pasto cortadito que era una belleza, era un parque, hermoso. Y empezamos a caminar por la orilla. Los papás iban por una y nosotras, por otra. Y el arroyo cada vez se ensanchaba más y más profundo, y no nos podíamos encontrar. Y por ahí vemos un caballo en el arroyo y miramos y el arroyo era limpito, limpito como agua para tomar, entonces veías todas la piedritas y veías peces y un caballo adentro. Entonces cuando vimos que estaba el caballo se nos ocurrió cruzar. Y cruzamos el arroyo. Ex alumna y auxiliar de la escuela 40 (Milstein coord.. 2004:46)
}

Revista Reflexão e Ação, Santa Cruz do Sul, v.18, n2, p.65-91, jul./dez. 2010 
La elección de los fragmentos escritos, de las imágenes, de los títulos fue realizada, tal como conté en el apartado anterior, sin que mediara una explicación de las razones por las cuales se procedía a seleccionar o descartar. Pero, como se puede ver en este ejemplo, no fue azarosa, ni caprichosa. A medida que los chicos iban seleccionando fragmentos e imágenes, yo advertía una coincidencia, una suerte de lógica implícita que ellos no expresaban con argumentaciones. ¿Cómo era posible esa coincidencia, esa coherencia, esos acuerdos? Estas cuestiones no son sencillas de responder. Nos ayuda remitirlas a formas de organización de la experiencia, la emoción y el afecto estrechamente ancladas en el cuerpo. Merleau Ponty (1984) explicó con mucha claridad la relación concluyente entre nuestros cuerpos, nuestras experiencias cotidianas y nuestros procesos de percepción, que incluyen la aprehensión de lo que denominó el espacio vivido. Bryan Turner (2001: 13), apoyado en esta idea planteó que la percepción de la realidad externa abarca experiencias corporales del mundo físico y la capacidad de manipular el mundo cotidiano a través de actividades motrices. Y consideró al lenguaje como necesariamente corporizado en esas formas materiales de la potencialidad del cuerpo. De ahí que pensar, hacer y sentir deben considerarse como actividades prácticas que requieren nuestra presencia corporizada. El caso de ese espacio físico, al que los adultos representan con la palabra baldío y los niños con el dibujo de dos árboles y una flor, evidencia vivencias, percepciones y criterios opuestos. Los adultos han corporizado la predisposición a ver los espacios urbanos con criterios utilitarios, instrumentales. Los niños, en este caso, anclaron su percepción y su lenguaje en sus capacidades de manipular y aprehender el mundo cotidiano desde y con sus cuerpos. Como indicaría Peter Mc Laren, sus cuerpos incorporaron ideas y también las generaron (1994:91). Incluso podríamos llegar a aceptar que, en gran parte estos libros, son 
la representación de la realidad corporizada o, en otros términos, la aprehensión corporizada de aspectos de la realidad.

Esto revela el potencial de la naturaleza reflexiva del intercambio con 1@s niñ@s cuando aceptamos el desafío que implica aprender a pensar, orientarnos, preguntarnos con sus marcos de referencia, en un proceso de interacción, diferenciación y reciprocidad entre nuestra reflexividad y las de ell@s (Guber; 2001:53). Los procesos de interacción estimularon y potenciaron los modos de relación intersubjetiva, básicos para producir conocimiento antropológico. $\mathrm{Y}$ en ambos textos quedó inscripta esa experiencia comunicativa del trabajo de campo entrelazada con las narraciones. Así, lo percibido, lo vivido, lo pensado y lo representado en los libros a través de sus distintos momentos y acciones, confirma la agencia de los niños en su capacidad de producción simbólica y en la constitución organizada de sus representaciones y creencias. Y a la vez, fortalece la idea que esa elaboración de sentidos es parte de un sistema simbólico compartido con los adultos.

De esta manera, subrayo la necesidad de insistir en que las prácticas que despliegan los niños no deben ser miradas ni pensadas, en términos de "culturas o subculturas infantiles", es decir, como entidades relativamente aisladas del mundo social (Milstein, 2006, Szulc, 2006). Los libros pueden también ser tomados como documentos que expresan de manera concluyente que las prácticas y las representaciones de los niños lejos de reflejar un "mundo infantil", conforman y constituyen la realidad social más amplia en la que los niños viven, lo que incluye sus posiciones en las relaciones sociales existentes. Sobre este último aspecto, también ellos decidieron "hablar" -recordemos cómo se presentaron en el primer libro, por ejemplo- y así delinearon sus lugares en el mundo social. Este carácter 
situado alude también a aquellos a quienes imaginaron como futuros lectores: "y seguro que cuando [el libro] esté, alguien lo va a leer", quedó escrito en la introducción del segundo libro.

Me interesa también insistir en el aspecto temporal de este posicionamiento. Johannes Fabian desarrolló un análisis crítico sobre las consecuencias negativas que ha tenido para el desarrollo del conocimiento antropológico la negación de la cotemporaneidad (coevalness). Como parte de su larguísima argumentación, sostuvo que los etnógrafos y sus interlocutores comparten una misma temporalidad que es una condición para que se establezca comunicación entre ellos y subrayó que, si el etnógrafo se engaña instalándose en una distancia temporal, se disipa el objeto de su investigación (Fabian; 1983: 32). Cuando nuestros interlocutores son niños, es difícil ubicarse en una misma temporalidad. Tendemos a engañarnos porque sentimos que ellos están pasando por un tiempo que nosotros ya vivimos. Nada más falaz, porque ellos viven nuestro mismo tiempo que es siempre diferente al tiempo que nosotros vivimos cuando éramos niños. El libro “Así vemos la Florida”, que reúne voces de otros niños y de los autores, presenta temas claves de la vida de la localidad -como las escuelas, las familias, los trabajos, la divisiones sociales y la política- que revelan hasta qué punto sus vidas cotidianas y las nuestras adultos- son co-temporáneas. Uno de los aspectos más enriquecedores del contenido de estos libros es, precisamente, que sitúan al lector en un tiempo compartido a través de comentarios, anécdotas o breves descripciones organizadas.

\section{El valor educativo de esta experiencia}

He intentado mostrar a lo largo de este artículo el modo en que los conocimientos, los afectos, las emociones y las expectativas se fueron entrelazando hasta lograr como 
producto una representación de lo vivido, expresada en dos libros. Dichos libros fueron compuestos utilizando una estrategia de "autoría plural" (Clifford; 1992) en la que la etnógrafa y los niñ@s hablaron, leyeron, dibujaron y escribieron. Para finalizar quisiera dedicarle un breve comentario a algunos rasgos que resalto como valor educativo de esta experiencia.

En primer lugar, me gustaría resaltar el placer. Estar en la escuela pero con la percepción de "tenerla para nosotros" revela un aspecto de ese goce. Caminar y correr juntos por las calles y decidir sobre la marcha qué hacer, hacia dónde ir, con quien conversar, qué fotografiar también era muy gozado por todos. Sentir que siempre eran esperados y bienvenidos fue otra forma de disfrute. Como lo explicó Patricia y luego fue publicado en el segundo libro:

Mi familia son muy trabajadores que no tienen tiempo para mí y mis hermanos y ahora que me uní con la antropóloga y mis amigos, son como una segunda familiar para mí" (Milstein coord.;2005:25)

Así podría continuar describiendo como en el flujo de las distintas actividades que desarrollábamos el placer motorizaba y daba sentido a lo que hacíamos. No soy experta en aprendizaje, pero sé que no es el goce ni el placer un tema de agenda cuando se piensa en términos educativos. Esta experiencia dejó esa impronta y puedo asegurar que es altamente recomendable para obtener éxito en el aprendizaje.

El goce está vinculado al interés, pero al interés genuino. Al interés que emerge de la motivación en cada uno, que no se corresponde con el imperativo "que se interesen". Durante el transcurso de toda la experiencia con los chicos me preocupé por estar atenta a lo que les interesaba, por tratar de entender la lógica práctica que los orientaba y en la mayor parte de los casos, por seguirlos, incluso, creyendo que no tenía mucha lógica. Y 
probablemente muchas veces no la tuvo, pero, al completar el tránsito de la experiencia, todo valió la pena. Hoy estoy en condiciones de afirmar que da resultados altamente positivos vincular el aprendizaje a un interés genuino, aunque esto implique muchas veces "perder el tiempo" desde el punto de vista adulto. Además, cuando damos lugar a que emerja el interés particular, también surgen modos diferentes de hacer, de mirar y de interpretar.

Esto último está vinculado a los lenguajes. A lo largo del proceso de producción de textos estimulé usos creativos de los lenguajes que ayudaran a producir alternativas posibles para construir sentidos. Recordemos que yo hice una gran parte del trabajo de transcripción y esto permitió que ellos pudieran lidiar con la gran dificultad que les imponía escribir Ese trabajo combinado con los lenguajes amplió la comunicación con el mundo y la interpretación del mismo.

Finalmente, el proceso completo de hacer trabajo de campo, componer un texto y presentarlo los colocó, como a los investigadores, en una posición de "autoridad". Autoridad que ellos asumieron cuando decidieron dedicarle un capítulo del libro a Fernando como el personaje reconocido como "el patriarca", y descartar a otros, como por ejemplo el Padre Jorge. Pero también autoridad que otorgaron sus lectores cuando, al año siguiente, un grupo de alumnos, orientados por una profesora y acompañados por dos madres visitaron, entrevistaron y se fotografiaron con Fernando. $\mathrm{Y}$ a fines de ese mismo año, en el acto de fin de curso, expusieron las fotos y un cartel que decía "El mito de Fernando", donde se relataba la historia desde su llegada a La Florida, que incluía párrafos tomados del primer libro publicado por nosotr@s. 


\title{
WRITING WITH CHILDREN: A CHANCE OF CO-AUTHORSHIP IN ETNOGHAPHIC RESEARCH
}

\begin{abstract}
This article shows how two groups of children of a primary school in a town in southern suburbs of Buenos Aires, Argentina, were included as interlocutors, interviewers, observers and co-writers in my ethnographic fieldwork, during 2004 and 2005. We published two booklets with the children in cooperation. They contain versions of the "others" and of the authors about the town. Both of them brought together a polyphonic set of stories and comments, along with the opinions of adults, youths and children from various ages, origins, families and occupations. The booklets provide intelligible versions of local social life by using a descriptive and narrative style and include maps drawn by children and photographed images. I develop an analysis of the particularities of the coauthorship with these children through an account of these work processes and the production of booklets. Then I discuss agency of children in aspects relate with their capacities as interpreters and authores and I propose innovative and creative ways to interact with children. Finally I argue that these modes can also impact educational processes.
\end{abstract}

Revista Reflexão e Ação, Santa Cruz do Sul, v.18, n2, p.65-91, jul./dez. 2010 
Keywords: Ethnography; fieldwork; children as co-writers; educative experience.

\section{Referências}

ATKIN, Beth. Voices form the fields. Childrens of migrant farmworkers tell their histories. Toronto: Little, Brown and Company, 1993.

CLIFFORD, James. Sobre la autoridad etnográfica. En Reynoso comp. El surgimiento de la antropología posmoderna. Barcelona: Gedisa, 1992.

GUBER, Rosana. La etnografía. Método, campo y reflexividad. Buenos Aires: Norma, 2001.

FABIAN, Johannes. (1983). Time and the other. How anthropology makes its object. New York: Columbia University Press. Memory against culture. Durham: Duke University Press, 2007.

MC LAREN, Peter. Peazgogía crítica, resistencia cultural y la producción del deseo. Buenos Aires: Aique, 1994.

MERLEAU-PONTY, Maurice. Fenomenología de la percepción. Barcelona: Alianza, 1984.

MILSTEIN, Diana. 2004. (Coord). Averiguando algo más. Leyendo la historia de nuestro barrio y nuestra escuela. Mimeo. 2005. Así vemos la Florida Mimeo.

MILSTEIN, Diana. “Y los niños por qué no?” en Avá Revista de Antropología, n ${ }^{\circ}$ Posadas: Programa de Postgrado en Antropología Social - UnaM, p. 49-59, 2006.

MILSTEIN, Diana. "Niños y niñas que enseñan: el grito de justicia" en Revista MAYU Medio Ambiente y Urbanización, $\mathrm{n}^{\circ}$ 69, IIED-AL Instituto Nacional de Medio Ambiente y Desarrollo de América Latina, p. 5-20, 2008.

MILSTEIN, Diana. La nación en la escuela. Viejas y nuevas tensiones políticas. Buenos Aires: Miño y Dávila, 2009.

Revista Reflexão e Ação, Santa Cruz do Sul, v.18, n2, p.65-91, jul./dez. 2010 
MILSTEIN, Diana. "Politics is also 'child's play'" en Teaching and teacher education. An international journal of research and studies, v. 26, n 1, Enero, p.136-143, 2010.

SPERBER, Dan. Etnografía interpretativa e Antropologia Teórica en O Saber dos Antropologos: tres ensaios. Lisboa: Ediçoes 70, 1992.

SZULC, Andrea. “Antropología y niñez: de la omisión a las 'culturas infantiles' en Wilde y Schamber comp. Culturas, comunidades y procesos urbanos contemporaneous. Buenos Aires: Paradigma indicial, p. 25-50, 2006.

TURNER, Bryan. "The Ends of Humanity: Vulnerability and the Metaphors of Membership." Hedgehog Review 3.2, p. 7-32. http://www.iascculture.org/HHR_Archives/Body/3.2CTurner.pdf . Acesso em 07/04/2010, 2001.

Data de recebimento: $12 / 07 / 2010$

Data de aceite: 17/09/2010 